\title{
LINGUISTICS
}

DOI: https://doi.org/10.33739/2587-5434-2019-10-19

\author{
Valerij Mokienko \\ Doctor of Philological Sciences, Professor, \\ St. Petersburg State University \\ (St. Petersburg, Russia) \\ e-mail: mokienko40@mail.ru
}

\section{FROM THE HISTORY OF ONE UKRAIAN-RUSSIAN LEXICAL AND PHRASEOLOGICAL NEOLOGISM}

\begin{abstract}
The problem of lexical and phraseological interaction has been the focus of Slavic and Russian scholars from both theoretical and practical points of view. From a general Slavic perspective, such an interaction reveals the similarities and differences between Ukrainian and Russian vocabulary and phraseology, which is the result of a long historical development. The practical aspect of its study reveals cases of interlingual interference that is difficult to learn, allows you to install the corpus of "false translator friends", and provides useful material for compiling bilingual dictionaries of interlingual homonymy (Kochergan 1989, Kolomiets 1988, etc.)

The scope and consequences of the Ukrainian-Russian lexical and phraseological interaction are truly immense and extremely diverse - from the deep etymological impulses in the evolution of individual words and expressions (Mokienko 2000) to systemic influences and linguistic rejections nowadays (Mokienko 2001). Nevertheless, with all their diversity in most of them dominant can be traced: Ukrainian language preserves more ancient formal and semantic characteristics close to common Slavic, which makes a dynamic study of Russian vocabulary and phraseology almost impossible to use the material of the Ukrainian language.
\end{abstract}

Key words: lexical and phraseological interactions, neologism, Ukrainian-Russian, history

\section{В. М. Мокиенко}

Доктор филологических наук, профессор, Санкт-Петербургский государственный университет

(Санкт-Петербург, Россия)

e-mail: mokienko40@mail.ru

\section{ИЗ ИСТОРИИ ОДНОГО УКРАИНСКО-РУССКОГО ЛЕКСИКО- ФРАЗЕОЛОГИЧЕСКОГО НЕОЛОГИЗМА}

\begin{abstract}
Аннотация. Проблема лексико-фразеологического взаимодействия интересовала и интересует славистов и русистов, как с теоретической, так и с практической точки зрения. С общеславистических позиций такое взаимодействие вскрывает сходства и различия украинской и русской лексики и фразеологии, ставшие результатом длительного исторического развития. Практический же аспект его изучения выявляет сложные для обучения случаи межъязыковой интерференции, позволяет установить корпус «ложных друзей переводчика», даёт полезный материал для составления двуязычных словарей межъязыковой омонимии (ср.: Kochergan 1989; Kolomiets 1988 etc.).
\end{abstract}


Масштабы и последствия украинско-русского лексического и фразеологического взаимодействия поистине необъятны и чрезвычайно многообразны - от глубинных этимологических импульсов в эволюции отдельных слов и выражений (Mokienko 2000) до системных взаимовлияний и языковых отторжений в настоящее время (Mokienko 2001). Тем не менее при всём их многообразии в большинстве из них прослеживается доминанта: украинские языковые факты хранят более древние, приближенные к общеславянским формальные и семантические характеристики, что делает динамическое исследование русской лексики и фразеологии без обращения к материалу украинского языка практически невозможным.

Ключевые слова: лексико-фразеологические взаимодействия, неологизм, украинскорусский, история

\section{ВВЕДЕНИЕ}

Проблема лексико-фразеологического взаимодействия интересовала и интересует славистов и русистов, как с теоретической, так и с практической точки зрения. С позиции общеславистической перспективы такое взаимодействие вскрывает сходства и различия украинской и русской лексики и фразеологии, ставшие результатом длительного исторического развития. Практический же аспект его изучения выявляет сложные для обучения случаи межъязыковой интерференции, позволяет установить корпус «ложных друзей переводчика», даёт полезный материал для составления двуязычных словарей межъязыковой омонимии (ср.: Kochergan 1989, Kolomiets 1988 etc.).

Масштабы и последствия украинско-русского лексического и фразеологического взаимодействия поистине необъятны и чрезвычайно многообразны - от глубинных этимологических импульсов в эволюции отдельных слов и выражений (Mokienko 2000) до системных взаимовлияний и языковых отторжений в настоящее время (Mokienko 2001). Тем не менее при всём их многообразии в большинстве из них прослеживается доминанта: украинские языковые факты хранят более древние, приближенные к общеславянским формальные и семантические характеристики, что делает динамическое исследование русской лексики и фразеологии без обращения к материалу украинского языка практически невозможным.

\section{РЕЗУЛЬТАТЫ И ДИСКУССИЯ}

Характерный пример украинско-русского неологизма - лексико-фразеологическая пара укр. водночас - рус. в одночасье. Образованные от древнего праславянского корня* čas 'время', это наречие и фразеологизм настолько близки по значению, что нередко русско - и украиноговорящими отождествляются, порождая межъязыковую омонимию. Переводчики, соблазнённые общностью формы и значения этой пары, используют послед -

\footnotetext{
* Исследование выполнено при финансовой поддержке РФФИ в рамках научного проекта № 19-012-00214 «Человек и общество в зеркале новой русской фразеологии».
} 
нюю как эквивалентную, не обращая внимание на тонкие семантические различия, которые для этой пары характерны. Один из типичных примеров - такая замена украинского слова русским выражением в популярной киевской газете «День», которая издаётся на украинском, русском и английском языках и переводится обычно весьма оперативно и качественно:

Що сталося за одну ніч із українським народом?! Хіба таке можливе: він, народ, раптом, водночас, увесь, як народ чеський - чеською, як поляки - польскою, французі французською, росіяні - російською, - заговорив рідною мовою? Людмила Тара. Щоденник. День, 15.09.98, с. 1.

Что произошло за одну ночь с украинским народом?! Разве такое возможно: он, народ, вдруг, в одночасье, весь, как народ чешский - на чешском, как поляки - на польском, французы - на французском, россияне - на русском, - заговорил на родном языке? Людмила Таран. Дневник.

На первый взгляд, русский эквивалент точно соответствует украинскому оригиналу. Ведь речь идёт о быстром, внезапном действии - потенциальной возможности мгновенного перехода всего украинского народа на пользование своим родным языком. Украинские и русские словари, однако, определяют соответствующие языковые единицы поразному. Академический словарь украинского языка даёт для водночас основную дефиницию ‘в то же самое время; одновременно' и лишь в качестве оттенка - 'одновременно с этим' (СУМ 1, 719), а в классическом словаре народного украинского языка Б. Гринченко близкие по образованию к этому наречию слова акцентируют именно значение «одновременности»: одноча́сний - 'одновременный', 'современный'; одноча́сно 'одновременно', ‘современно (с чем)'. одноча́сник - 'современник’ (Гр. 3, 42). «Большой толковый словарь русского языка» (БТС, 703) определяет выражение в одноча́сье как 'в очень короткий промежуток времени, сразу'. Любопытно, что как в Большом академическом словаре, так и в авторитетном словаре под редакцией Д. Н. Ушакова оборот в одноча́сье формально не выделяется (хотя контексты отражают его актуальность), а дефинируется лишь само слово одночасьве 'промежуток времени в один час; короткий промежуток времени' (БАС 8, 708), ‘промежуток времени в один час; около одного часа' (ТСРЯ 2, 768). Вероятно, причина этого - следование лексикографической традиции В. И. Даля, в словаре которого оборот в одноча́сье даётся лишь как иллюстрация к существительному одноча́сье 'один час, часовой срок' (Dal' 2, 654). Характерен и «разброс» функциональностилистических помет этого русского слова и выражения: в последним словаре они характеризуются как обл. (областное), в Большом академическом - как прост. (просторечное), а в «Большом толковом»- как разг.-сниж. (разговорно-сниженное).

Формальная и стилистическая разнородность при характеристике русского выражения в одночасье свидетельствует о его амбивалентном, пока ещё не выкристаллизовавшемся статусе. И действительно, хотя (как увидим ниже), этот оборот употреблялся в классической литературе давно, он приобрёл особую активность именно в современном языке - причём стал одним из излюбленных оборотов журналистов в постперестроечный период. Вот почему его можно характеризовать как своего рода фразеологический неологизм, т. е. оборот, особо актуализировавшийся со времён Перестройки (Mokienko 2003: 66-67).

В каких же значениях он теперь употребляется? 
Самой доминирующей для него сейчас, пожалуй, является семантика «быстрого, моментального возникновения, перемены (обычно к лучшему) чего-л.»:

В нашем городе появился новый вид спорта - синхронное фигурное катание. Но, возникнув 8 одночасье, он может сразу и умереть. СПб. вед, 16.05.97, с. 5.

Прецедентов, сколько ни искали, в мировой практике найти не удалось: обычно, если уж природный газ из какой-нибудь системы отключается на года - эта система считается пришедшей в негодность. В Ереване к этой аксиоме прибавилось еще несколько дополнительных факторов риска. В годы кризиса около 18 процентов жителей столицы отъехали в более благоприятные регионы СНГ и дальнего зарубежья, и газовые краны в закрытых квартирах, оставаясь невостребованными, вполне могли оказаться открытыми. К тому же больше половины Еревана перешло на газовые баллоны, которые присоединялись к стационарным трубам нередко весьма кустарно. И если бы вдруг во всём городе в одночасье появилось централизованное газоснабжение - масштабы трагедии, по мнению специалистов, было бы даже трудно представить. Пол-Еревана просто взлетело бы на воздух. М. Вартаньян. В Ереван вернулся газ. - МК, 9.09.97, с. 2.

Реформы в одночасье создали на прилавках ассортимент продуктов, правда, по совершенно неприличным ценам! КП, 30.08.96, с. 6.

Лас-Вегас можно считать младенцем, дата рождения которого доподлинно известна - 26 декабря 1946 года. В том далёком захолустном послевоенном городке проживало около 10000 человек, сегодня число населения города перевалило за миллион. Мафиозные деньги в одночасье превратились ц сказочный город в пустыне, где до сего дня правят четыре человеческие страсти: Игра, Развлечения, Секс, Еда. О. Новицкая. Город «Жёлтого дьявола». - Самовар, 1997, ноябрь, с. 8.

Как неудержимое веселье, бывает, сменяется приступами уныния, так и в Южной Корее откровенная радость вскоре уступила недобрым предчувствиям. В одночасье на мостах появились вооружённые блокпосты, на всех объектах государственного значения - усиленная охрана, в международном аэропорту Кемпо в капитанский багаж изъяли даже ножницы, а наиболее волнующим занятием для корейцев стало гадание - будет или не будет война. Изв., 20.02.97, с. 3.

Жизнь в Ереване нежданно-негаданно в одночасье оживилась. КП, 10.02.98, с. 1.

Что же всё-таки нас ждёт дальше? Климат в обществе в одночасье не оздоровить, от стресса и страха перед завтрашним днём не избавиться. АиФ - «Москва», 1999. - № 19, c. 22 .

Через неделю в отделе морали «Комсомольской правды» меня подвели к полке с наклейкой «Почта Е. Талызина»- там лежала, с каждым днём утолщаясь, пачка писем со всех концов страны. Со мной спорили, ко мне обращались за советом незнакомые люди, я в одночасье стал адресатом для сотен парней и девчат, пожилых людей. Выходит, задел за живое? Е. Талызин. Жить как прежде не буду. КП, 10.01.88, с. 1.

На самое незначительное повышение размера и числа пенсий сегодня не находится средств. Кроме того, число пенсионеров в одночасье возросло почти вдвое - после принятия законов о ранних пенсиях работникам образования и здравоохранения. Изв., 14.02.97, c. 2.

Древние русские города Изборск и Печоры в одночасье стали Ирбоской и Петсери и были эстонскими целых двадцать лет, пока не пришло время Советского Союза. КП, 29.07.97, с. 5 .

Близко к этому и значение «мгновенного изменения (в лучшую сторону положения, статуса кого-л.»: 
Не было сомнений, что Окуличос бросил вызов силам весьма влиятельным и многоликим. Средства массовой информации и народная молва в одночасье сделали паневежского предпринимателя чуть ли не национальным героем, этаким «терминатором» безжалостным борцом со злом. СПб. вед., 19.02.97, 4.

Согласитесь - нельзя стать гражданином в одночасье. Для этого нужен запас смелости, мужества, убеждений. С. Батраченко, Г. Игитян и др. Не обманем их надежд! КП, 10.06 .89 , с. 1 .

Той дождливой ночью премьер-министр Джон Мейджор, возвращаясь с работы, подобрал на улице бездомного котёнка и «усыновил». Супруга этот поступок одобрила, и котёнок в одночасье из «нищего» превратился в «принца». КП, 27.17.97, с. 2.

Антонимичным является весьма частотное значение «быстрая, мгновенная гибель кого-л., чего-л., полное разрушения чего-л., беда»:

Мы потеряли родителей в один из страшных дней далёкого 1936 года, когда папу и маму увёз из дома ночью «чёрный воронок»... В одночасье были разрушены семейный очаг и любовь, а пятеро детей осиротели. Российская газета, 11.08.99, с. 2.

Посёлка Чоботы, что находился неподалеку от писательского городка Переделкино, теперь на карте нет. Московский мегаполис поглотил это местечко ещё лет пятнадцать назад, и размеренная сельская жизнь рухнула в одночасье. КП, 18.02.97, с. 5.

Лившиц, Ясин, Дубинин, наконец, Черномырдин - достаточно здравомыслящие политики, чтобы в одночасье разрушить всё, чего с таким трудом добивались. АиФ, 1996. - № 48 , с. 5 .

В том же негативном семантическом русле - употребления оборота, характеризующие «мгновенную потерю кого-л., чего-л., лишения чего-л.»:

В состав «Русского дома в Литве» входят русские общественные организации, русские газеты и представители российских фирм, сотрудничающих в Литве. Всех нас объединяет проблема 350 тысяч русских, которые в одночасье оказались за пределами своего Отечества. НДР и Регионы, 25.10 .99 , с. 5.

Первой «медной» волной из Козельска смыло все газы, самовары, дверные ручки. Теперь покатил «второй вал» - алюминиевый. $B$ одночасье козельчане лишились ложек, вилок и прочей легковесной утвари. Российская газета, 14.08.99, с. 6.

О правах инвалида Бурова, оказавшегося в одночасье без средств, на иждивении матери, которая в январе получила пенсию за ноябрь, никто из больших и малых его начальников даже не обмолвился. А. Калинин. Смерть в капустном чане и т. п. - Изв., 14.02.97, с. 5.

Это разгулявшаяся Алла, вместе со всем народом вкладывающая деньги в сомнительный фонд «Властилина» и в одночасье теряющая там несколько сотен тысяч долларов... АиФ, 1997. - № 10 (март), с. 3.

$B$ одночасье леса исчезают не только у Шекспира. Они исчезают прямо у нас под носом. Московский комсомолец, 13.02.98, с. 2.

Взрыв в пятиэтажке в одночасье оставил без крова более 50 человек. СПб. вед., 17.02.98, с. 1 .

Пользователи компании «America on-line», рискнувшие установить у себя фильтрующую программу под названием «Net Nanny», в одночасье лишились доступа к электронным угодьям округов Миддлсекс, Эссекс и Сассекс. Исключительно по той причине, 
что в названии этих округов присутствует сакраментальное словечко. Общая газета, 7.13.08.97, с. 12.

Двор деревенский и дом Барсику сразу же понравились. Дня три ходил он осматривался, обнюхивал новое местожительство, но ни с кем во дворе ни знакомства, ни дружбы не заводил. Потом в одночасье Барсик исчез. Звали, искали, горевали, записку у колодца повесили на случай, если кот кому-то на глаза попадётся. Нет, исчез, как в воду канул. В. Песков. Кот-вездеход. Шанс, 2000, январь, с. 2.

Молодая жена богача в одночасье становится вдовой. Российская газета, 9. 07.99. с. 20.

Наконец, логическим продолжением отмеченных семантических доминант нашего выражения являются и более частные - напр., «прекращение какой-л. деятельности» или «переоценка ценностей». При этом, разумеется, главный семантический временно́й стержень - 'мгновенно, внезапно' - сохраняется и в таких случаях:

«Человеку отмерено где-то лет 80, так что у меня в запасе есть ещё лет 30, которые необходимо провести интересно и с пользой», - сказала она себе и в одночасье уволилась с работы. КП, 30.12.97, 7.

По подсчётам учёных, если онкологические заболевания вдруг в одночасье исчезнут, продолжительность человеческой жизни в среднем увеличится всего на 3 года. АиФ, 1997. - № 49, с. 20.

Понятно, почему такая книга написана в наше время и в нашей стране, где в одночасье были поставлены под сомнение многие ценности жизни и в том числе - традиционное распределение ролей во взаимоотношениях мужчины и женщины. Общая газета, 713.08.97, с. 11.

Аналитический обзор актуальных ныне контекстов русского выражения в одночаcbe, как видим, показывает, что его временна́я семантика достаточно зримо отличается от украинского паронима водно́час. Значение 'одновременно', которое не «проглянуло»ни в одном из русских контекстов, весьма чётко и последовательно отражается украинскими текстами, что хорошо зафиксировано Большим академическим словарём украинского языка (СУМ 1, 719):

Буть агрономом і поетом, Їй Богу, можна водночас. М. Рильский. Поеми.

До Капітана Капітанича Павлик Олеся наблизились майже водночас. Донч.

Хороша, барвиста водночас проста мова Івана Вазова зробила приступним його роман для найширших кіл читачів. П. Тичина.

И для текстов современной украинской прессы такая семантическая характеристика наречия весьма типична:

Водночас у ході слухань (а їх загалом набралося вже більше десятка) спливло чимало фактів злочинного нехлюйства та командирської безтолковості деяких вищих чинів. Україна молода, 16.08.2000, с. 6.

«Це підгодоване, обивательске місто», - обізвав столицю В. Луценко, але заявив водночас, що через місяць, 7 листопада, усе-таки закликатиме «підгодованих обивателів» на демонстрації. Вечірний Київ, 9.10.98, с. 1.

Как видим, при общем корне и глобально временно́й семантике укр. водночас и рус. в одночасье оказываются «ложными друзьями переводчика» и имеют разную направленность. Украинское слово характеризует прежде всего одновременность действий и протекающих событий, а русское - их мгновенность, внезапность.

Чем же обусловлены эти семантические различия? 
Ответ на этот вопрос следует искать в этимологии и истории украинско-русского межъязыкового омонима. Этимологию, причём весьма лапидарную, собственно, предлагает лишь один словарь - этимологический словарь украинского языка, характеризующий наречие водна́чác как «результат контаминации словосочетания в один час и наречия одноча́сно (ЕСУМ 1, 415). Для украинского слова такая расшифровка корректна, но требует существенного семантического уточнения, объясняющего различия украинского и русского слова час. В украинском языке и большинстве фразеологизмов это слово имеет древнее общеславянское значение 'время': в останній час, деякий час, того часу, найближчим часом, на довгий час и т. П. Древняя семантическая инерция этого слова, конечно же, законсервировалась и в некоторых русских фразеологизмах: в добрый час, не в добрый час, неровён час и др. (Mokienko 2005: 26-30). Однако в современном русском языковом сознании оно давно уже потеряло обобщающее значение времени и закрепилось как характеристика его весьма конкретного отрезка - 60 минут. В результате такого развития рус. час стал межъязыковым омонимом укр. час и требует перевода иным словом - година. И в укр. обороте в один час, который контаминировался с наречием одноча́сно, древнее общевременное значение сохраняется, позволяя буквально перевести его как «в одно [и то же] время».

В русском языке также имеется выражение (правда, устаревшее) в один час (Под влиянием характерной для русского языка актуализации слова час оно, однако, имеет иную семантику - 'очень быстро, мигом' (ФСРЛЯ 1995: 2, 360):

- Вижу, моя воительница совсем сбрендила: распялась и угасла в один час. Н. Лесков. Воительница.

- Ты гляди, Максимыч, - со стариком надо жить осторожно, он тебя в один час вокруг пальца обернёт. Этакие вот старички едучие - избави Боже до чего вредны! М. Горький. В людях.

Хотя такое значение, как видим, во многом - результат «осовременивания» слова час на русской почве, но и оно имеет более старую традицию и вероятно заложена в семантическом синкретизме праславянского слова * čas. Ведь лишь такой синкретизм может объяснить наличие «краткосрочного» значения для др.-рус. оборота въ одночасье 'за очень короткое время' (XVI и XVII вв.): А что Дмитрей привёл кобылицу гнһдую, и она на вербной недһлһ въ понһдһльникъ въ одночасье сдһлалась, умерла въ день. Переп. Хован. (XVII в.). (СРЯ XI-XVII вв. 12, 290). Ср. также др.-рус. томь часh, в тыли часы в скором времени' (Sreznevskiy 3, 1071).

Временна́я раздвоенность русского оборота особенно явно прослеживается в русских диалектах, демонстрируя различные направления его семантического развития, впоследствии закреплённые как доминантные для русского и для украинского литературных языков. Вот некоторые фиксации такого рода: пенз. в одноча́сье 'ночью, в середине ночи' («Дело было в одночасье»); енис., свердл. 'в короткий срок, быстро’ («Мотрена в одночасье яишницу сварила»); влад., урал. 'одновременно, в одно и то же время' («В одночасье со мной приехал») (СРНГ 23, 55); симб. 'скоропостижно, внезапно' («Схватило вдруг, в одночасье помер!» (Dal' 2, 654); куйбыш., урал. в одноча́с 'быстро, неожиданно'; новосиб. ‘одновременно' (СРНГ 23, 55); пенз., в одноча́сь 'скоропостижно, внезапно'; одно́чась 'то же'; вят., костром., свердл. в одноча́с, одноча́сно 'скоропостижно, внезапно'; арх. 'тут же, в то же время, быстро'; арх., перм. 'скоро, тотчас'; арх. 'в одно время, разом' (СРНГ 23, 55). Доминантной для русского диалектного континиума, правда, и здесь остаётся семан- 
тика «мгновенности, внезапности», что позволяет предположить, что новосиб. в одноча́с 'быстро, неожиданно'; 'одновременно' - скорее всего, украинского происхождения: известно, что говоры Новосибирской области имеют смешанный характер в связи со значительным притоком населения из Украины. Ср. также кар. одночасно 'скоропостижьно' («Когда прилив крови, так одночасно помирают, а она - сутки. Он одночасно помер»); кар. одночась 'тотчас, сразу' («Ушёл на берег, да одночась в воду и пал») (СРГК 4, 158); новосиб. Одночастни тебя! 'полушутливое бранное выражение'.

В русских народных говорах хорошо представлена и словообразовательная модель нашего паронима, напр.: кар. в односу́тки 'в течение суток' (СРГК 4, 158); в одина́чье 'один раз' (СРГК 4, 156); в одноме́стье 'кучно, в одно место' (СРГК 4, 156) и т. п. Ср. также нача́сье, злоча́сье, одноча́сье, бесча́сье и др. (ИИ СРНГ, 147).

Представленные языковые факты убедительно показывает, в каком направлении шло развитие лексико-фразеологического омонима в русском и украинском языках. Если в украинском он остался накрепко «пришвартованным» к древнему значению общеславянского слова * čas, то в русском он семантически менялся под влиянием его сужения. При этом произошла довольно ощутимая смена семантических доминант. Первоначально рус. в одночасье характеризовало «гибельные», «разрушительные» процессы, происходящие предельно быстро, внезапно - особенно чью-либо скоропостижную кончину, большое несчастье. Эта семантическая акцентовка, как мы видели, отражена и в древнерусском, и в диалектном употреблении нашего оборота, откуда она «перекочевала» и в контексты классиков русской литературы, закреплённые Большим академическим словарём (БАС 8, 708; 17, 791; Kveselevich 2003: 474) и некоторыми толковыми словарями:

Деревня сгорела дотла. Мужики в одночасье потеряли всё и сделались нищими. М. Е. Салтыков-Щедрин, Деревенский пожар.

- Крепко меня люди обидели, - начальники. А тут и Бог, вдобавок, убил: жена молодая да сынишко в одночасье померли. В. Г. Короленко. Убивец.

- Кто полезет к [Порт-]Артуру в такую непогоду? Если под берегом так мотает, то что же делается в море? В одночасье корабль обледенеет и пойдёт ко дну. В. А. Степанов. Порт-Артур.

Злые языки и по сей день говорят, что муж Татьяны - Сенафонт - чахленький, плюгавенький - умер в одночасье. Панфёров. Бруски.

Повылезло из неизвестных щелей и подворотен множество новых, невиданных никогда прежде людей, попёрло всё это по просторам жизни скопом, массой, силой. $B$ одночаcье одичало всё, поползло по швам, полезло шерстью дикой. Напаскудили кругом... $B . A p-$ тёмов, Диссидент.

\section{ЗАКЛЮЧЕНИЕ}

В современной русской литературе и публицистике, как мы видели, произошла своеобразная семантическая «рокировка» этого выражения. Теперь оно часто употребляется и как характеристика положительных изменений, возникновения чего-либо нового и желанного, хотя и его «разрушительная» семантика также неплохо сохранилась. Украинское же наречие водно́ча́с не таит в себе никаких отпечатков внезапности и мгновенности происходящего, а сохраняет в себе доброе и старое значение «единовременности». Сохраняя в то же время и инерцию древнего взаимодействия и взаимовлияния двух близкородственных славянских языков. 


\section{REFERENCES}

БАC (1948-1965): Slovar' sovremennogo russkogo literaturnogo yazyika. Tt. 1-17. (Bolshoy akademiche-skiy slovar). M.-L.: izd-vo Akademii nauk SSSR,

БТС (1998): Bolshoy tolkovyiy slovar russkogo yazyika. Sost. i gl. red. S.A. Kuznetsov. - SPb.: «Norint», $1536 \mathrm{~s}$.

Гp.: Grinchenko B. D. (1909, 1969, 1997) Slovar ukrayinskoyi movi. Tt. 1-4. Kiyiv, 1909; Kiyiv, 1969; Kiyiv, ta in.

Dal'. (1955): Dal' V. I. Tolkovyiy slovar' zhivogo russkogo yazyika. 3-e izd. Tt. 1-4. M. ECУM (1983-2003): Etimologichniy slovnik ukrayinskoyi movi. Tt. 1-4. Kiyiv: Naukova dumka,

ИИ СРНГ (2000): Inversionnyiy indeks k Slovaryu russkih narodnyih govorov. Sostavili F.P. Sorokoletov, R.V. Odekov. Pod red. F. Gledni. - SPb: izd-vo SPbGU, 570 s.

Kveselevich (2003): Kveselevich D.I. Tolkovyiy slovar nenormativnoy leksiki russkogo yazyika. Okolo 16000 slov. - M.: 000 izd-vo «Astrel», OOO izd-vo «AST». - 1021 [3] s.

Kolomiets (1988): Kolomiets N.F. Sopostavitelnoe issledovanie frazeologicheskih sino-nimov russkogo i ukrainskogo yazkuov i razvitie ukrainsko-russkogo dvuyazyichiya // Dvu-yazyichie v sovetskom obschestve. Tezisyi resp. nauchn. konf. 11-13 maya 1988. - Vinnitsa, 170-172.

Kochergan (1989): Kochergan M.P. Slovar russko-ukrainskih mezh'yazyikovyih omonimov (soderzhanie i printsipyi postroeniya) // Russkiy yazyik: vzaimodeystvie s ukrainskim. metodika prepodavaniya v usloviyah bilingvizma. Kiev: UMK VO, 23-34.

Mokienko (2000): Mokienko V. M. K ukrainsko-polskim leksicheskim i frazeologicheskim vzaimodeystviyam (ukr. halyava - pol. cholewa - rus. halyava, na halyavu) // Studia z filologii sIowia

Mokienko (2001): Mokienko V. M. Yazyikovyie izmeneniya v russkoyazyichnoy presse Ukrainyi // Sprachwandel des Russischen im Transformationsprozess am Ende des 20. und zu Beginn des 21. Jahrhunderts (= Rostocker Beitr

Mokienko (2003): Mokienko V.M. Novaya russkaya frazeologiya. - Uniwersytet Opolski: Instytut Filologii Polskiej. - Opole, 168 s.

Mokienko (2005): Mokienko V. M. Zagadki russkoy frazeologii. - 2-e izd., pererab. - SPb.: «Avalon», «Azbuka-klasssika», $256 \mathrm{~s}$.

Srezn. (1893-1912): Sreznevskiy I. I. Materialyi dlya slovarya drevnerusskogo yazyika po pismennyim pamyatnikam. - T. 1-3. - SPb.

СРГ: Slovar russkih govorov Karelii i sopredelnyih oblastey / Glavnyiy redaktor A. S. Gerd. Vyip. 1-6. SPb.: izd-vo SPbGU, 1994-2005.

СРНГ (1965-2006): Slovar russkih narodnyih govorov. Pod red. F.P. Filina i F.P. Sorokoletova. Vyip. 1-40 (izdanie prodolzhaetsya). L.-SPb.

СРЯ XI-XVII vv. (1975-2002): Slovar' russkogo yazyika HI-HVII vv. - Vyip. 1-26. M.: «Nauka»,

СУМ (1970-1980): Slovnik ukrayinskoyi movi. - V 11 t. - Kiyiv: «Naukova dumka», ТСРЯ (1934-1940): Tolkovyiy slovar russkogo yazyika // Pod red. D.N. Ushakova. Tt. 1-4. L. ФСРЛЯ (1995): Frazeologicheskiy slovar literaturnogo yazyika kontsa HVIII-HH v. Pod red. A. I. Fedorova. Tt. 1-2. Novosibirsk: «Nauka» 
Information about the author: Valerij Mokienko - Doctor of Philological Sciences, Professor, Departement of the Slavic Philology, Saint-Petersburg State University, the head of the Phraseological School of the St.-Petersburg University. Professor Dr. h.c. em. Ernst-MoritzArndt-University Greifswald (Germany); the Honour Professor of the Olomouc University (Czech Republic) and the President of the Phraseological Commission by the International Commitee of Slavists. Chairman of the Scientific Council of International ScientificPedagogical Organization of Philologists "WEST-EAST" (ISPOP), Chairman of the Scientific Editorial Council of Scientific Journal "WEST-EAST".

e-mail: mokienko40@mail.ru

Сведения об авторе: В. М. Мокиенко - Доктор филологических наук, профессор, СанктПетербургский государственный университет (Россия), Университет им. Эрнеста Морица Арндта (Германия), Оломоуцкий университет (Чешская республика). Презедент Международного комитета славистов. Председатель научного совета Международной научнопедагогической организации филологов «Запад - Восток», председатель научноредакционного совета международного научного журнала "WEST-EAST" .

e-mail: mokienko40@mail.ru

Manuscript received: $11 / 25 / 2018$

Accepted for publication: $01 / 25 / 2019$

Рукопись получена: 11/25/2018

Принята к печати: 01/25/2019 